in all respects and with a correction of $+2.25 \mathrm{D}$. $\mathrm{sph}$. and $+1.0 \mathrm{D}$. cyl, ax. $80^{\circ}$ read $6 / 5$ and Jaeger 1 .

The left eye showed a marked degree of microphthalmus, a shallow anterior chamber and well marked threads of persistent pupillary membrane. The vision with +9.0D. sph. was only hand reflex.

The accompanying sketch shows the condition of the fundus. The optic papilla was represented by a very deep and extensive cup, brilliantly white in colour. The lower part was deeper than the upper, and, dividing the two parts, was a transverse strand of what appeared to be fibrous tissue. The vessels were anomalous, in the lower part of the cup disappearing suddenly over its edge, but in the upper part passing gradually from the retinal level on to the cup. The cup was surrounded by a white ring of varying. width edged in places by a finely-dotted pigment. In the upper part of the ring some ill-developed choroid was seen.

Between the disc and the macula there was a small area of bare sclera oval in outline. The macular area was occupied by a large oval area roughly white in colour but stippled over with fine brownish dots. The major axis of the oval was transverse, and the whole was slightly sunken. Two choroidal vessels were seen in the upper and outer part of this oval and another down and in. Down and out there was a large collection of fine pigment which extended around the periphery throughout.

\title{
ON CERTAIN ABNORMAL CONDITIONS OF THE MACULAR REGION USUALLY CLASSED AS COLOBOMATA*
}

\author{
BY \\ IDA C. MANN \\ LONDON
}

Certain abnormalities of the macular region are usually classed as congenital colobomata. The main reasons for so regarding them appear to be, in the first place, that there is never any certain history of onset, though there may be a history of sudden discovery of the defect, and in the second place, that they are quite stationary throughout life. To this it may also be added that they have been found occasionally in very young children, and that a certain number of them occur in association with some other abnormality known to have been present at birth. On these grounds they are classified as congenital. The term "coloboma" appears to be

* Work done under a grant from the Medical Research Council. 
applied to them to-day merely to bring them into line with other, more common, developmental anomalies of the eye. In the first instance, however, the term seems to have been used under a misconception as to their mode of production.

The interest of such defects of the macula lies solely in the questions of diagnosis and aetiology, since in the present state of our knowledge it appears impossible to suggest any treatment.

The usual description given in textbooks of the ophthalmoscopic appearance of a coloboma of the macula is that of von Ammon, who published the first case in 1852. It is said to be a round or oval area situated at the posterior pole of the eye (at or near the macula). It has a narrow pigmented margin and a pearly. white base, which is ectatic. Actually, however, from clinical observation and examination of the records of published cases, it appears that this description is not applicable.in a large number of cases of undoubted congenital macular defect. We can, as a matter of fact, distinguish at least three main types with occasional intermediate cases.

These three types are in what I believe to be the order of frequency :-

1. The pigmented macular coloboma.

2. The non-pigmented macular coloboma.

3. The macular colobona associated with abnormality of bloodvessels.

1. The pigmented macular coloboma seems to be the least rare form of the defect. It has been described by Bock, who divided colobomata maculae into two types, the first, corresponding to the present group and involving the choroid only, the second (the non-pigmented coloboma about to be described) involving the retina as well. A very typical example of the pigmented type is seen in Fig. 1 which shows a drawing of a patient seen by Mr. Cole Marshall, to whom I wish to express my thanks for permission to reproduce it. The figure shows the right fundus. At the macula is a more or less circular patch. This is covered with dense irregularly arranged masses of pigment. The chorio-capillaris layer of the choroid is absent and in places the sclera and a few large choroidal vessels can be seen deep to the pigment. There is no ectasia of the base. Normal branches of the arteria centralis retinae course over the patch without interruption, showing that the disturbance is at any rate deep to the inner molecular laver of the retina. The appearance of the patch, with its heaping of pigment and destruction of the chorio-capillaris laver of the choroid, resembles that of a patch of healed choroiditis. In such patches one often finds, especially if the inflammation has been of the chronic irritative type, a similar diffuse hyperplasia of pigment without disturbance of the overlying retinal vessels. 
Abnormal Conditions of the Macular Region

2. The non-pigmented coloboma maculae is the classical type. It is a round or oval patch with a punched-out appearance. The base is pearly white, like the sclerotic which forms the floor of a typical coloboma of the choroid. This base is practically always slightly hollowed out and may be measurably ectatic. Around the

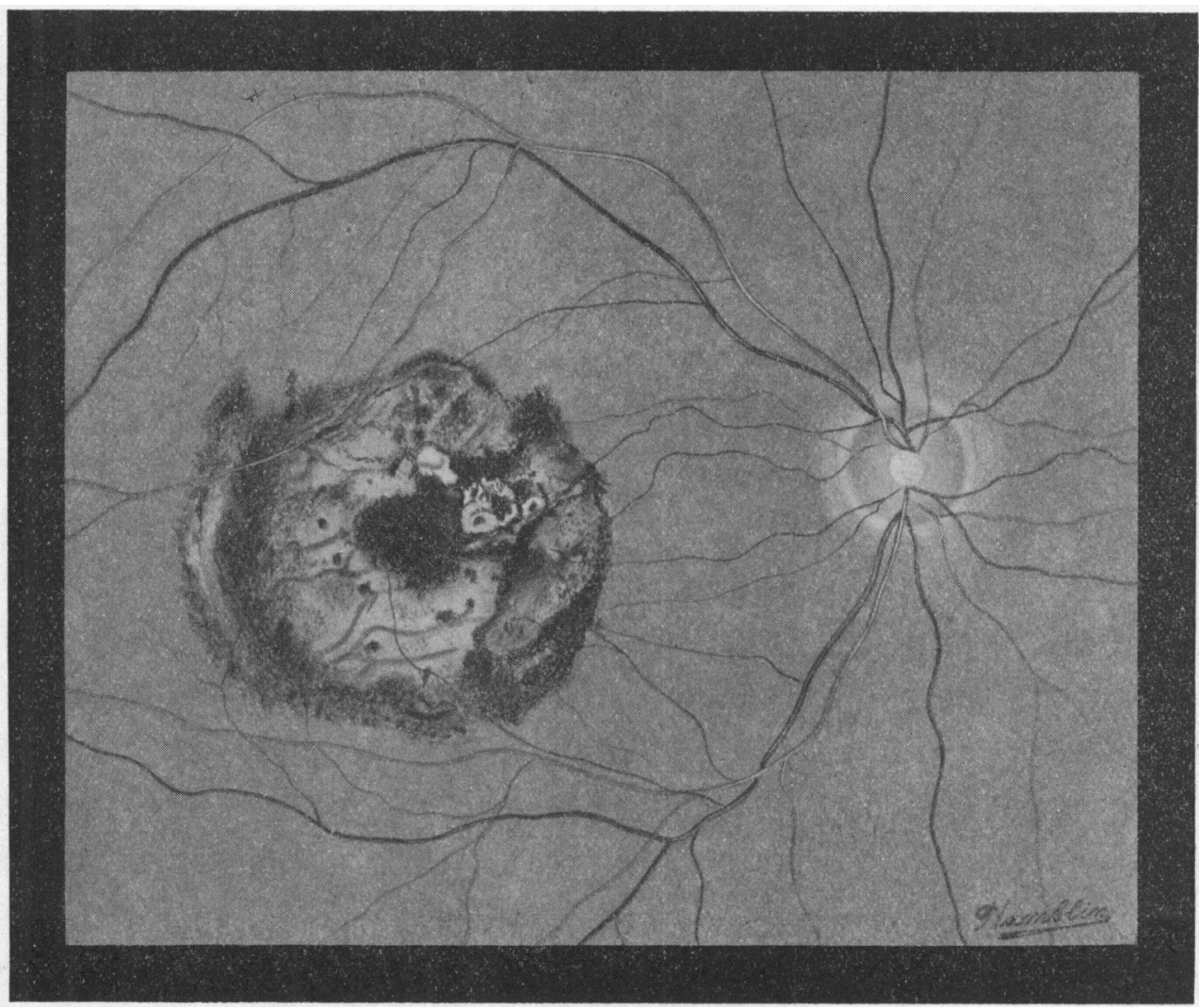

edge of the white area is a band of pigment. This may be merely a narrow line, but is often more profuse than this. In many cases the' pigment shows irregularities and local overgrowths along the margins of the white patch. In practically all cases of this type the retinal vessels stop abruptly at the margin of the patch and do not course over it, showing that the retina is involved as well (this is Bock's second type of coloboma). Two striking examples of this type of case are seen in the drawings illustrating Ernest Clarke's and Goulden's papers in the present number of this 
journal. In both cases the floor of the coloboma is ectatic and practically free from pigment. In Clarke's case there is much pigmentary disturbance around the edge, the individual patches of pigment having each a pale centre, so that a broad circinate pigment border is produced. There is, in addition, marked thinning of the choroid between the macula and the disc. In Goulden's case the pigment border is very narrow and the

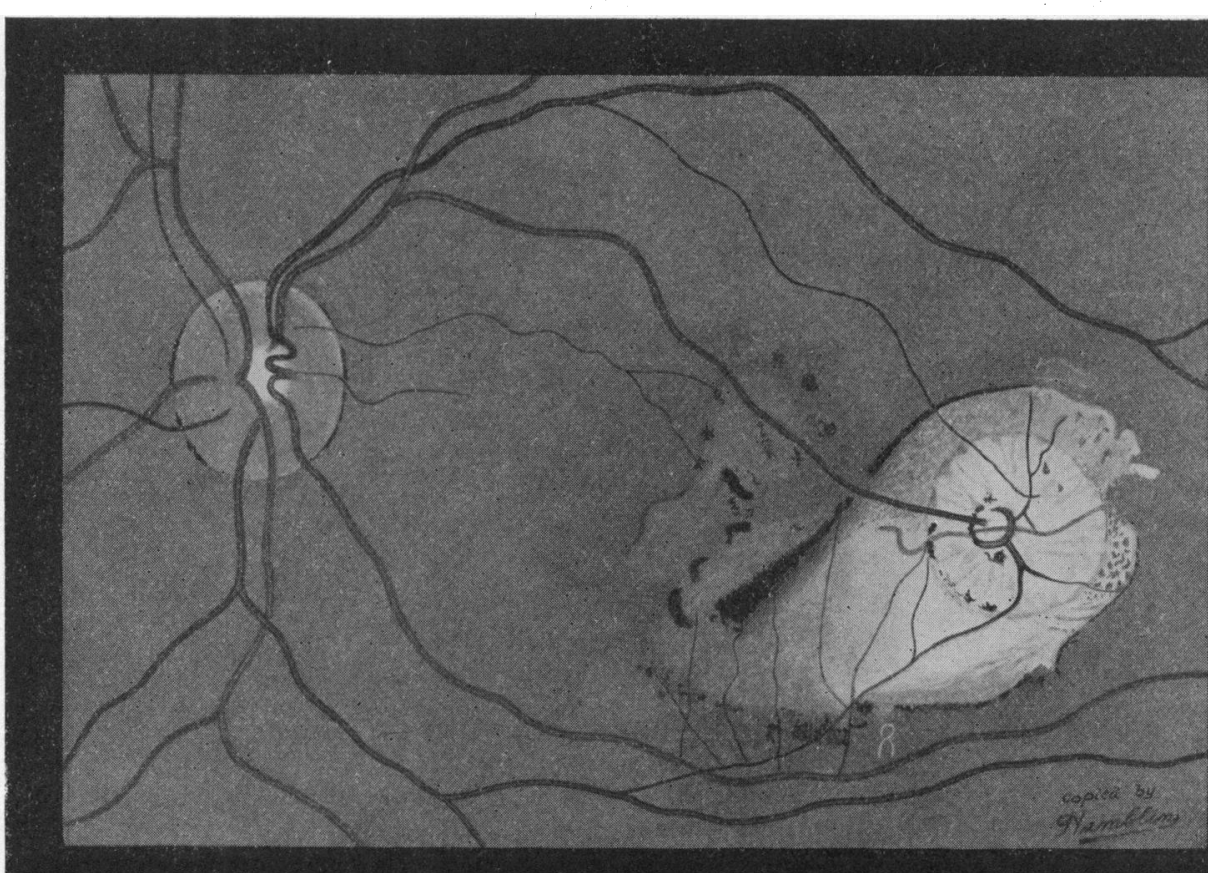

FIG. 2.

Drawing, after Beaumont, of a macular coloboma showing abnormal anastomosis of vessels.

patch resembles the classical description. In addition, in this case there is a coloboma of the optic disc, a fact of great importance as its presence at once stamps the condition as congenital.

3. The association of a macular coloboma with the presence of abnormal vessels is rare, but sufficient cases have been reported to make it obvious that such a class does exist. The vascular anomaly may apparently take the form either of an abnormal anastomosis of vessels in the patch or of a vessel passing forwards from it into the vitreous. The anastomotic type is represented by a case shown before the Ophthalmological Society in 1891 by Beaumont. The appearance is seen in Fig. 2 . 
The disc is on the left. At the macula on the right is a circular white patch without much pigmentation (i.e., a macular coloboma of type 2), but with the peculiarity that the upper temporal branch of the arteria centralis retinae runs into it and anastomoses with a vessel apparently coming forward through the floor of the coloboma. From this vessel a branch passes which drains into the lower temporal branch of the central vein of the retina.

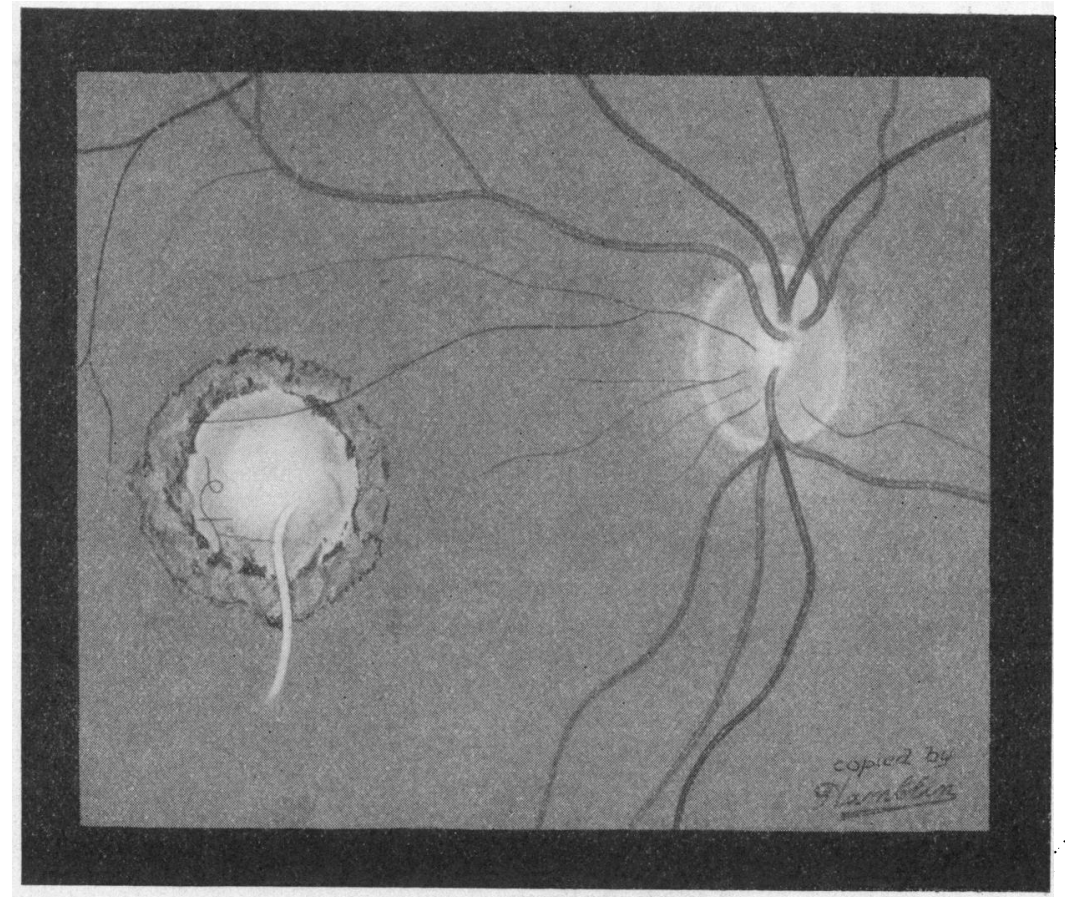

FIG. 3.

Drawing, after Quarry Silcock, of a vessel passing forwards from a macular coloboma into the vitreous.

The other type of vascular anomaly met with, namely, a vessel passing from the coloboma forwards into the vitreous is illustrated in Fig. 3. This shows a case reported by A. Quarry Silcock in 1900. The coloboma, as in Beaumont's case, is of the non-pigmented type and from its centre a pale cord-like structure projects forwards. In the original account of the case it is stated that the central part of the posterior vascular capsule of the lens was persistent and that the cord from the macula ran on to the equator of the lens in its lower inner segment. A somewhat similar case was shown by Williamson-Noble (for M. G. Pearson) at the Ophthalmological Section of the Royal Society of Medicine 
in June, 1926. In this case the periphery of the coloboma was pigmented and the cord-like structure passing into the vitreous could not be traced as far as the lens (which latter was normal).

These three clinical types of coloboma maculae are, when well marked, perfectly distinct and separate. In certain cases, however, the assigning of the defect to one or other class is a matter of some difficulty, since intermediate types appear to occur. For example a dense heaping of pigment in the periphery may be associated with a small white ectatic hole in the centre, so that it is uncertain whether it is the pigmentation or the ectasia which is the more striking feature. Again, practically all grades of pigmentation are known, so that types 1 and 2 may be linked up by a series of intermediate types. Yet again, cases in the third group show sometimes much and sometimes little pigmentation, so that, apart from the vascular abnormality they might be assigned either to group 1 or group 2. The occurrence of this gradation between types in themselves perfectly separate seems to point to the possibility of some true aetiological connection between them and incidentally furnishes a strong argument in favour of classifying. them and considering them merely as three different manifestations of the same pathological entity.

The question now arises of the mode of production of coloboma maculae. It is the object of this paper to attempt to show that the developmental theories which have enjoyed much popularity in the past are mainly untenable. If this be the case the advisability of discarding the name "coloboma" must be considered, since it might be taken to imply a connection between the anomaly under discussion and that known as "typical coloboma of the choroid," whereas the mechanism of the latter is undoubtedly explicable. on developmental lines while the former is a pure aberration bearing no relation to normal embryology.

The theories which can be advanced in explanation fall roughly into two groups :- .

\section{(a) Developmental and \\ (b) Pathological.}

\section{(a) Developmental Theories.}

It is obvious from clinical examination alone that the defect is not confined to a single tissue. That the retina is involved is seen from the presence of a scotoma corresponding to the patch (even though normal retinal vessels may course over it). That the pigment epithelium is abnormal is seen from its absence or hyperplasia, as the case may be, while the absence of the choriocapillaris furnishes one of the most striking characteristics of the condition. In some cases (but not in all) the outer layers of the choroid and even the sclera are involved as well. In embryological 
parlance therefore the defect can be said to implicate both neural ectodermal and mesodermal structures.

There are three possibilities to be considered :-

1. Coloboma maculae may be due to an). anomaly of growth of the whole optic.cup. i.e., the primary

2. It may be due to a localized anomaly of fault may be in differentiation of some of the pluripotential neural ectoderm. cells of the walls of the optic cup.

3. It may be due primarily to a defect in the development of the mesoderm surrounding the optic cup.

1. The first theory is the oldest and is in great part founded on misconceptions of normal development. It is of interest in that it marks an attempt to bring congenital macular disease into line with other deformities due to abnormal growth of the optic cup, and hence seeks to justify the use of the term "coloboma" in both cases.

When the older anatomists looked at the arrangement of the nerve fibres in the retina they were struck by the now well-known appearance of a horizontal raphé running outwards from the disc across the macular region. This line, from which the nerve fibres appear to diverge, and which none of them ever cross, was extremely suggestive of a closed fissure, and its discovery led embryologists to adopt the idea that it marked the final position of the foetal ocular cleft. If this were the case then the maculat must have been developed by the fusion of two areas on either side of the cleft. Since it was well known that the foetal cleft ran at first downwards it became necessary to postulate a rotation of the optic cup in order to bring the line of the fissure into the position of the macula. Many attempts were made to prove that this rotation took place. Vossius first of all attempted to demonstrate a rotation of the optic cup on its long axis through $90^{\circ}$. He stated that it occurred after the third month. Strahl and Henkel later called this in question and substituted for it a theoretical rotation of $45^{\circ}$ only, on the ground that the foetal cleft never ran directly downwards, but downwards and outwards from the first. They considered that the rotation occurred before the third month.

The chief arguments adduced to prove the rotation were :-

(1) That the arteria centralis retinae entered the optic stalk at first directly below and later to the outer side.

(2) That the superior rectus muscle is at first lateral to the levator palpebrae superioris and later lies immediately below it.

(3) That the fibres in the optic nerve run a spiral course. 
If the theory of rotation were correct then it was possible to explain both typical downward coloboma and coloboma of the macula as arrests of closure of the foetal fissure. If both closure of the cleft and rotation of the globe were interfered with then a coloboma downward resulted, but if rotation occurred normally, although closure of the cleft did not, then a coloboma of the macula was produced. This theory held the field for some time in spite of an obvious drawback, namely, that a normal macula and a coloboma downwards have been known to exist in the same eye. This fact alone shows that failure of closure of the foetal cleft will not account for both defects.

The theory of rotation of the optic cup was questioned by many embryologists, among whom Deyl and Dedekind did much to cast doubt upon it. That the macula had any connection with the foetal fissure was finally disproved by the work of Chievitz, and it is generally conceded to-day that no rotation occurs and that the macular region bears no relation to the fissure. This theory of abnormal growth of the optic cup should therefore be finally abandoned, and incidentally one should realize that the most cogent reason for naming the defect a coloboma has been removed also.

2. In the early stages of development of the eye the cells of the inner wall of the optic cup are pluripotential. That is to say they are apparently all alike and yet by their subsequent division they will give rise to a diversity of tissues, for example, nerve fibres, rods and cones, ciliary glands and muscle fibres, inter alia. It was first pointed out by Coats that anomalies of differentiation of these cells were possible, so that they gave rise to patches of abnormally placed tissues. This theory of faulty histological differentiation of the wall of the optic cup may be called in in an attempt to explain macular coloboma.

There is a certain amount of evidence that there is an interaction during development between the pigment of the outer wall of the cup and the chorio-capillaris layer of the choroid, so that they develop pari passu and if either is for any reason absent the other will be abnormal also. Whether the formation of pigment is dependent on the presence of the chorio-capillaris or vice versa is not known, since they appear practically simultaneously in development. If, therefore, certain of the cells of the outer layer of the cup in the macular region failed to differentiate into pigment cells, the choroid in contact with this region might secondarily fail and a non-pigmented coloboma would result. This theory, however, does not account for the ectasia seen in this type of case, neither does it at all take into consideration the deeply pigmented type of coloboma. Although this last might be said to be due to abnormal differentiation of cells of the inner wall of the optic cup into pigment-bearing cells, in addition to those of the outer wall, 
one is faced with the difficulty that the chorio-capillaris layer is absent in this type as well.

The question therefore arises whether the primary failure is in neural ectoderm at all. A brief study of the normal development in man will adduce yet another argument against this view.

The development of the macula is intimately connected with the histological differentiation of the whole retina. As is well known

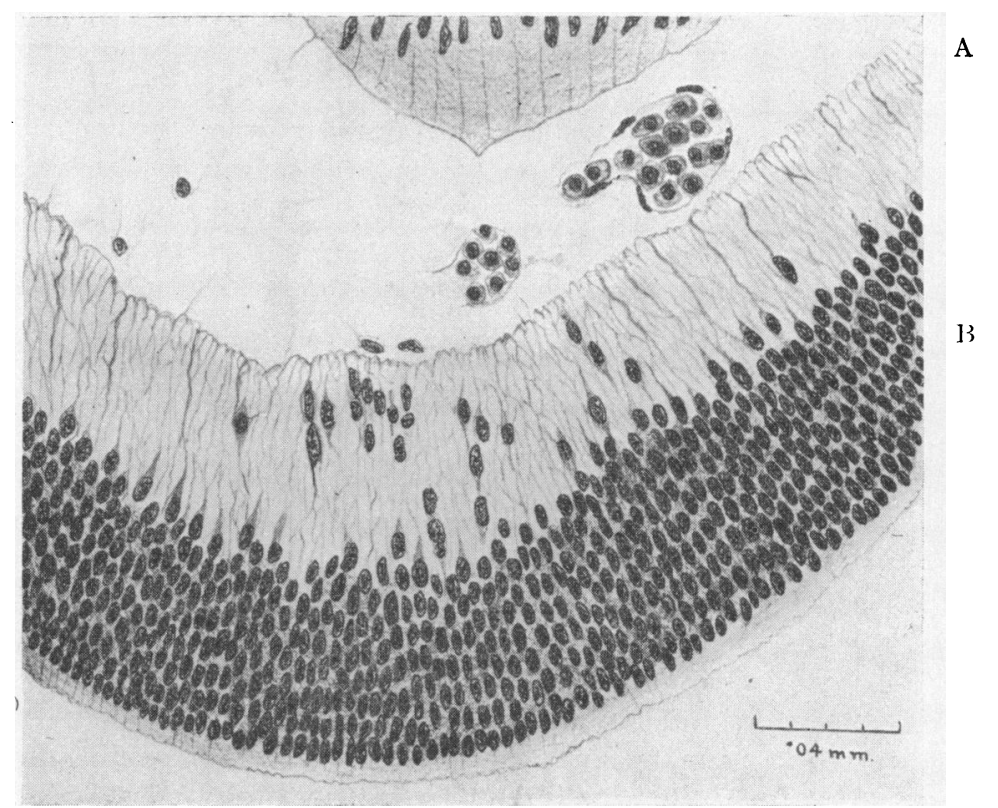

FIG. 4

Section through the retina at the posterior pole of the optic cup of a $12 \mathrm{~mm}$. human embryo.

$\mathrm{A}=$ marginal zone.

$\mathrm{B}=$ zone of primitive nuclei which are beginning to migrate into $\mathrm{A}$.

the retina (with the exception of its pigment epithelium) is developed by the differentiation of the neuro-epithelium of the inner wall of the optic cup. At first this wall consists merely of a nucleated and a non-nucleated zone. The nucleated zone (primitive layer) lies externally and the non-nucleated (marginal layer) internally. The inner layers of the retina (from the internal limiting membrane to the amacrine cells) develop by migration of cells from the primitive (nucleated) layer into the marginal layer. The first cells to migrate inwards and to differentiate are the ganglion cells and the fibres of Müller, and the first indication of their migration can be seen in human embryos of $12 \mathrm{~mm}$. At 
this stage the area over which differentiation is beginning is very small and is situated at the posterior pole a little above the (epithelial) optic disc. From this region differentiation spreads rapidly towards the periphery of the cup all round, but throughout the whole course of retinal development the region of the posterior pole always shows a slightly more advanced stage than any other, so that it appears that every step in the process of differentiation is initiated here. This dominance of the posterior pole in the matter of histology is illustrated in Figs. 4 and 5. Fig. 4 shows the retinal layer of the optic cup of a $12 \mathrm{~mm}$. human embryo. The migrating ganglion cells and nuclei of the fibres of Muiller are seen over a small area at the posterior pole, the rest of the marginal layer being empty.

Fig. $5 a$ shows a much later stage (65) $\mathrm{mm}$.) in an area near the posterior pole. The following layers can now be recognized : nerve fibres, ganglion cells, amacrine cells and nuclei of fibres of Müller, bipolar cells and nuclei of cones (see figure). Fig. $5 b$ shows a section through the same retina in the anterior region. The less advanced stage of specialization is obvious, only two cellular layers being as yet developed.

Up to the third month the future macular region has served as the starting point for each histological change and it seems possible that any process sufficiently strong to prevent its development before this period would also seriously affect the differentiation of the rest of the retina. After the eighth month the macula itself begins to develop and the changes which constitute its differentiation do not spread beyond it.

At first the retina is completely avascular. In early stages it appears to draw its nutriment from the blood-vessels of the vitreous rather than the choroid since there is (even up to the third month) no true cohesion between the retinal wall of the optic cup and the pigment epithelium, the remains of the cavity of the primary optic vesicle being quite evident between them. At the beginning of the fourth month the arteria centralis retinae makes its appearance and its branches spread among the nerve fibres into the inner layers of the retina. The temporal branches are well established by the fifth month. It does not seem likely that, if a patch of aplasia had arisen by aberrant development before the third month, the retinal vessels at their subsequent appearance would run in it in a normal way.

Thus, from the normal histology of the rest of the retina in cases of macular coloboma, and from the presence of normal retinal vessels in the coloboma, it seems probable that the area centralis in these cases developed as usual at least up to the fifth or sixth month. Primary defect of the neural ectoderm can therefore be ruled out as a cause of congenital macular disease. 
3. The third developmental possibility to be discussed is that of primary abnormality of the mesoderm, with secondary failure of ectoderm. It has been contended that, since the presence of pigment appears to be related to the presence of the choriocapillaris, if this latter failed to develop over a given area pigment would be absent in the outer wall of the optic cup over the same

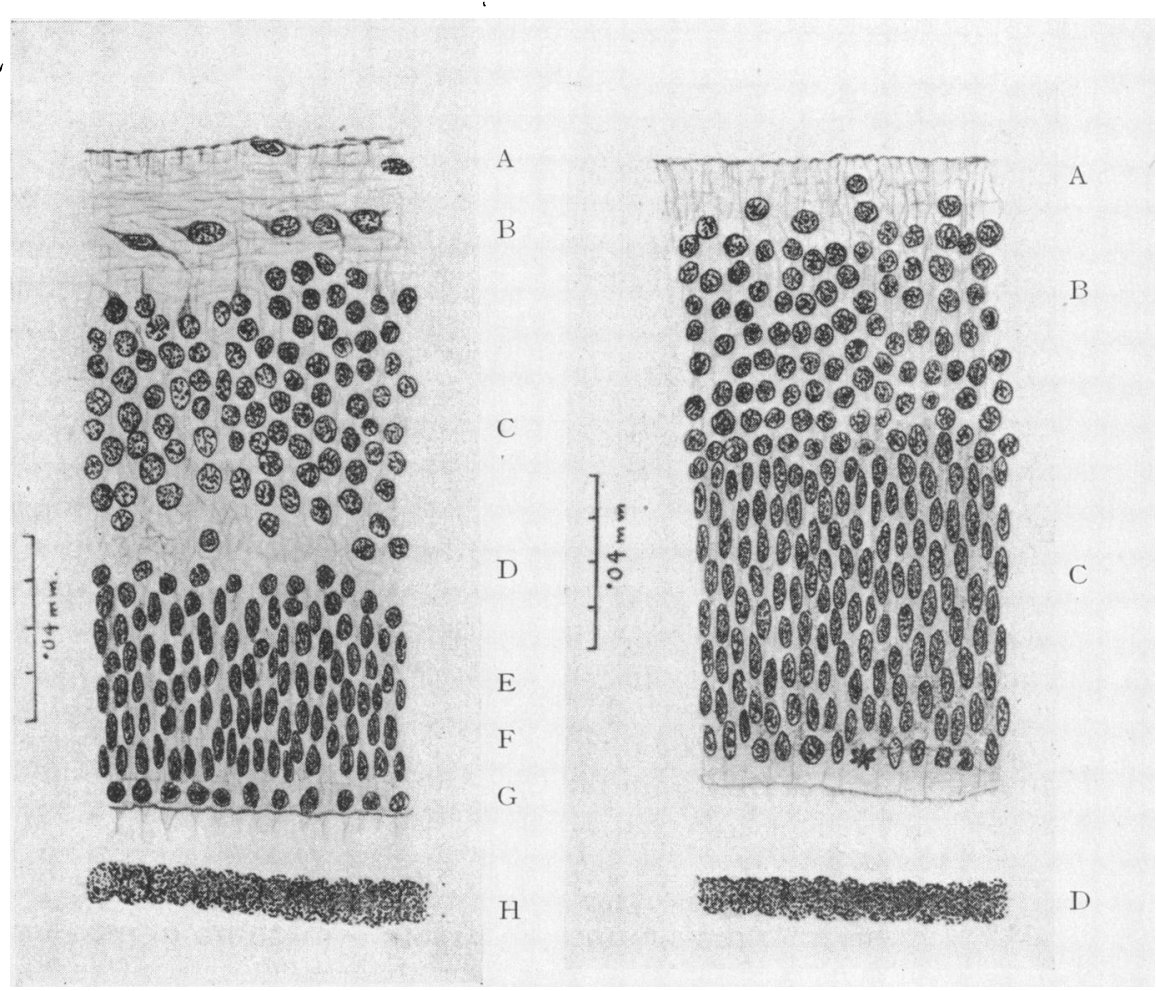

Figs. $5 a$ and $b$.

Sections through the retina of a $65 \mathrm{~mm}$. human foetus ( $3 \mathrm{rd} \mathrm{month}$ ). $a$ shows the retina near the posterior pole.

$A==$ nerve fibre layer bounded by internal limiting membrane.

$\mathrm{B}=$ =layer of ganglion cells.

$\mathrm{C}=$ layer of amacrine cells and nuclei of fibres of Müller.

$\mathrm{D}=$ transient fibre layer of Chievitz.

$\mathrm{E}=$ =layer of nuclei of bipolar cells and rods.

$\mathrm{F}=$ nuclei of cones.

$\mathrm{G}=$-primitive cones.

$\mathrm{H}=$ =pigment epithelium .

$b$ shows the retina in the anterior region.

$\mathrm{A}=$ narrow marginal layer.

$\mathrm{B}=$ primitive inner nuclear layer.

$\mathrm{C}=$ primitive outer nuclear layer.

$\mathrm{D}=$ pigment epithelium. 
area, and a white patch would result. We have no evidence, however, that contact with pigmented epithelium is necessary to the normal development of the inner wall of the optic cup, so that the associated failure of the retinal layer in macular coloboma is not explained. Neither is the deeply pigmented type elucidated by this theory.

The supposed primary failure of the chorio-capillaris has been explained on developmental lines as failure of that anterior branch, of a short posterior ciliary artery, which supplies the choroid in the macular region. It must, however, be pointed out that the ciliary arteries are not end-arteries. They do not each supply a sharply limited area, but merely take part in an exceedingly free anastomosis. There is ample anatomical evidence of their variability in number and arrangement in the normal eye without any corresponding vấriation in the vascularity of the choroid.

The most conclusive argument against this view, that failure of a ciliary artery to develop would cause a localized absence of the chorio-capillaris, is, however, the fact that the chorio-capillaris is completely formed before any of the ciliary arteries are recognizable. It is not therefore dependent on them for its development in the first place. In early stages $(10-14 \mathrm{~mm}$.) the chorio-capillaris is supplied by four vessels in the region of the equator (these subsequently become the venae vorticosae). It is quite possible that failure of one of them would lead to a failure of a portion of the chorio-capillaris, but if this were so the defect would be quadrantic and not a circular localized patch. It therefore seems unlikely that an initial failure of mesoderm is responsible for the production of a macular coloboma.

\section{(b) Pathological Theories.}

We see that primary failure of development (either of ectoderm or of mesoderm) will not account for the condition. It seems probable that the tissues involved have been normal up to a point and that subsequent destruction of them has occurred. The possibility of the presence of pigment, of retinal vessels, and of large choroidal vessets in the coloboma all point to this.

Three pathological theories must be considered. Two of them can be dismissed with very little discussion, since sufficient data are not forthcoming to prove or disprove them. The third theory presents greater possibilities.

(1) Coloboma maculae may be the result of a haemorrhage at birth.

(2) It may not be truly congenital but may have resulted from a choroiditis in infancy and so may fall into line with other cases of post-natal inflammatory macular disease.

(3) It may be the result of an intra-uterine choroiditis. 
1. The first theory is alluring on account of the work of Naumoff, von Hippel, Thomson and Buchanan, Sleich, Stumpf and Sicherer, Juler, and others on the frequency of injuries to the eye at birth. These observers have shown that haemorrhages in the area centralis (visible immediately after birth) are (even after normal delivery) much more common than was at one time thought. Such a haemorrhage, which would not be suspected and could not be diagnosed without ophthalmoscopic examination, might lead to the formation of a patch of disorganization in the choroid which would only be discovered later. Against this theory are the statements made by Juler, at the annual meeting of the Ophthalmological Society last year, to the effect that the haemorrhages are usually retinal and are spread out in thin sheets in the nerve fibre layer. A certain number are sub-hyaloid and a massive choroidal haemorrhage is extremely rare. It does not seem likely that lesions of this nature would produce the clinical picture of coloboma maculae in later life. Further observations on the end result in cases known to have shown intraocular haemorrhage at birth would definitely settle this point and are badly needed.

2. The truly congenital nature of coloboma maculae has not been proved with absolute conclusiveness, though it is in most cases presumptive. The ophthalmoscopic picture is so often that of a healed patch of choroiditis that, apart from the history, one would often have no hesitation in making such a diagnosis. It must not be forgotten that until macular colobomata have been seen in newborn children their congenital nature cannot be taken for granted.

As will be shown later, in a certain number of cases it is possible to hazard a guess as to the period of development at which the pathological change took place, but in a large number this is impossible and it must therefore be admitted that in them we cannot say with certainty that the defect is not due to an infantile. choroiditis.

3. The question of the occurrence of intra-uterine inflammation and of its results is a wide one. The possibility of the infection of the developing embryo by micro-organisms or their products must be admitted on purely anatomical grounds for all placental mammals, but the result of such infection is extremely controversial. It is probable that the earlier the infection occurs the less do its results resemble the inflammatory reactions of adult tissues. Thus if the process starts very early (first month) the growth of the embryo is probably so fundamentally interfered with that it becomes incapable of developing at all. If infection occurs during the major part of the organogenetic period (i.e., up to three months) the usual inflammatory reaction does not occur, but growth may be retarded and perverted, so that a congenital abnormality may 
result. This is not usually recognizable as inflammatory, but is often referable from its nature to an aberration of growth at some particular period. The later the infection occurs the more the results of it will resemble processes well known in post-natal life, so that infections occurring just before birth may give rise to exactly similar manifestations in mother and foetus.

The theory that macular coloboma is due to intra-uterine choroiditis affords the best explanation of the condition so far put forward.

In the first place a certain number of cases have been examined microscopically and the findings shown to be practically identical with those in healed choroiditis of known post-natal origin. Descriptions have been published by Bock, Deyl, Hess, and Zimmermann among others. All the cases agreed in showing disappearance of the chorio-capillaris. In some all the layers of the choroid were absent : in Deyl's case some of the larger vessels were present, with pigment along them, running in a fibrous scar tissue resembling sclera. In Hess's case (in a rabbit) the choroid was entirely absent and in addition the sclera was thinned and ectatic. With regard to the retina the findings varied. In Zimmermann's case only (in a dog) was it entirely absent. In the rest it was present in a more or less disorganized condition. Deyl's case is suggestive, as the inner layers of the retina were continuous over the coloboma, the outer layers only being destroyed. In Bock's case remains of all the layers were recognizable. The findings point very definitely to an abnormal process starting in the chorio-capillaris, and resemble in every particular the microscopic appearances in cases of healed choroiditis of varying severity. The destruction of the smallest vessels, the surrounding of the larger ones by scar tissue, the occasional proliferation of pigment and the reduction of the retina to a more or less disorganized membrane adherent to the choroid, are all found to perfection in cases of chronic irritative inflammation of the choroid (c.g., disseminated choroiditis). The well-known "selective action" of certain infective processes on the adult macula cannot be denied and there seems no reason to suppose that the foetal macula is any more immune. Being indeed the most highly specialized and latest developed region of the retina it is probably the first to succumb.

It can be shown that on the theory of inflammation the three clinical types and the gradations between them can be brought into line under one heading, a manoeuvre which is impossible on any other theory.

These three types probably represent the end-results of an intrauterine choroiditis acting at three different periods of development.

The first (pigmented) type bears most resemblance to the effects of choroiditis in the adult and probably arises latest in foetal life, 
during the eighth or ninth month. It cannot arise before the fifth month since the retinal vessels and often some of the layers of the retina itself are normal over the patch of destruction : the sclera is not in these cases ectatic, a fact which points to its late origin at a time when the sclera is becoming more solid and fibrous and less liable to soften under the influence of infection. The ophthalmoscopic and microscopic picture is that of an inflammatory process, more irritative than destructive.

The second (non-pigmented and ectatic) type of case shows the effect of a much more severe and acute inflammation. The pigment cells in the centre of the patch have been utterly destroyed, not stimulated as in the first type. Around, the edges, where the toxins are becoming more dilute it is true they may proliferate. At the centre the sclera is also involved, softened, and thinned so that it vields under the intraocular tension and becomes ectatic. The overlying retina is also destroyed, together with the vessels in it, which stop abruptly at the edge of the patch. These cases probably arise earlier than the first group, possibly during the fifth or sixth month (since the retinal vessels seem to have been present) at a time when, the tissues being less resistant than they are later, an inflammation would have a destructive rather than an irritative effect on them. In some cases the patch may be irregular, as if two or more foci had fused. In Clarke's case, described above, one can almost see outlined the large central focus surrounded by small satellites, each with its white central area of destruction and its ring of pigment proliferation at the margin.

The production of type 1 or type 2 may therefore depend either on the severity of the inflamımation or on the time at which it occurred. Probably both factors are involved. It is easy to see on these grounds how it is that intermediate types occur so readily.

The third type, namely, that associated with abnormality of ressels, is extremely interesting. The case of Beaumont quoted above may be explained as a patch of severe choroiditis occurring late in foetal life. It has led, after destruction of the membrane of Brüch and the pigment epithelium, to the formation of a secondary anastomosis hetween retinal and choroidal vessels in a mass of scar tissue replacing the choroid. This was indeed the explanation given by Beaumont himself when the case was first shown and is perfectly satisfactory. It has since been suggested that the vessel in the centre of the white patch was a "ciliary artery becoming cilio-retinal," and an analogy has been drawn between this and the cilio-retinal arteries so often seen at the edge of the disc. It must not be forgotten, however, that while cilio-retinal arteries perforating at the edge of the disc are normal in many animals and extremely common in man, there is no evidence whatever in comparative anatomy or embryology that a ciliary artery 
can pass through the membrane of Brüch, unless this has first been destroyed by inflammation or trauma.

The second type of case in group 3 (with a vessel passing from the macula into the vitreous) belongs to an earlier stage of development than any of the rest discussed. The vessel attached to the macula has occasionally been called the hyaloid artery, but since the macula is not developed in the line of the foetal fissure it is

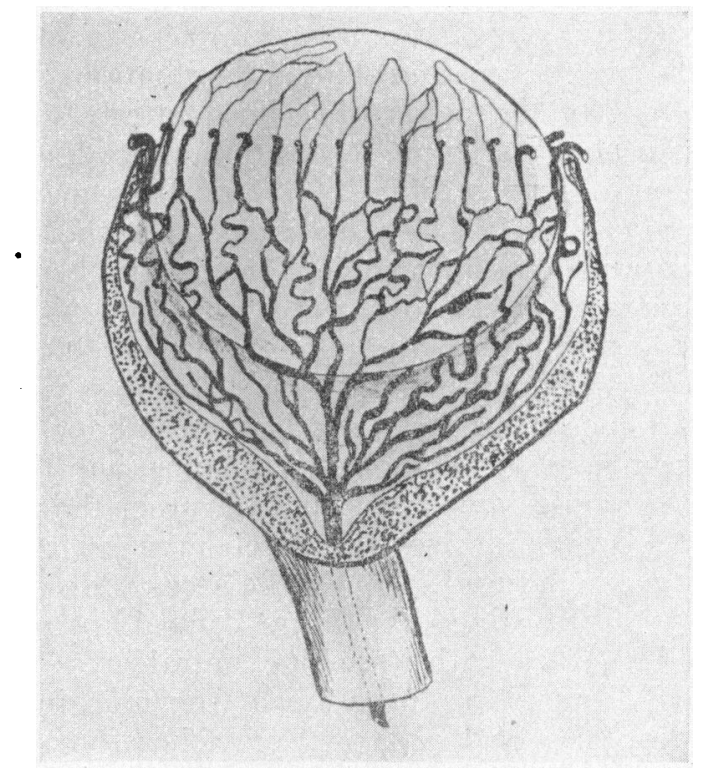

FIG. 6.

Scheme (after Versari) showing the vessels in the interior of the optic cup at the $40 \mathrm{~mm}$. stage.

obvious that the hyaloid can never enter the eye through nor be attached to the macula. There is no normal stage in man at which a vitreous vessel projects from the macula. There is, however, a stage in which the vitreous is full of vessels, many of which are in close approximation to the retina, though never in human embryos actually attached to it. Such a stage (approximately $40 \mathrm{~mm}$.) is shown schematically in Fig. 6. The main trunk of the hyaloid is seen giving off innumerable branches, the vasa hyaloidea propria, which fill the cavity of the optic cup. It will be seen that many of them pass forward to the lens, the posterior vascular capsule of which they join in the equatorial region.

These rasa hyaloidea propria begin to atrophy during the early part of the third month or sooner. If the retina became involved in a destructive inflammation of the choroid before their disappearance it is possible that the disturbance of its surface might 
cause one of the most peripheral of these vessels to become adherent to the site of the lesion and this vessel might then acquire a secondary anastomosis with choroidal vessels, the membrane of Brüch (which is present at the beginning of the second month) being destroyed. This acquired extraneous blood supply would allow of the persistence of this vessel after its fellows had atrophied. The diagnostic test of such a vessel is the destination of its anterior end. If it is one of the vasa hyaloidea propria it will pass to the equator of the lens, and this it does, as we have seen in the case reported by Silcock. In Pearson's case it does not reach the lens, but is otherwise similar in appearance. We can therefore hazard a guess that a macular coloboma with a vitreous vessel attached is due to an inflammation occurring before the atrophy of the iasa hyaloidea propria (i.e., at the end of the second month or during the third). The presence or absence of pigment in such cases depends on the severity of the pathological process.

To sum up, we can say that all the types of so-called macular coloboma so far observed can be brought under one heading only by postulating the occurrence of intra-uterine choroiditis. The exact type of defect produced depends on-

(a) the time during development at which the lesion occurred, and

(b) the nature of the inflammation, i.e., whether destructive or irritative.

The diagnostic tests to be Applied are :--

1. The presence of normal retinal vessels over the defect. This points to an irritative affection after the sixth month.

2. The presence of ectasia and absence of retinal vessels. This points to a more destructive process, with or without an earlier onset, e.g., fourth to fifth month.

3. The persistence of one of the rasa hyaloidea propria. This is diagnostic of a process occurring before the end of the third month.

\section{REFERENCES}

Beaumont, W. M. -Trans. Ophthal. Soc. U.K., Vol. XI, 1891.

Bock. - Die angeb. Colobom des Augapfels. Wien, 1893

Chievitz, J. H. - Die Area u. Fovea centralis Retinae beim menschlichen Foetus. Intern. Zeitschr. f. Anat. u. Physiol., Bd. IV, S. 201, 1887.

Collins, E. T.-Proc. Ophthal. Sec. Roy. Soc. Med. (Discussion). Oct, 1926. and Mayou, S.-Pathology and bacteriology of the eye. 2nd edition, 1925.

Dedekind. - Beiträge zur Entwickelungsgeschichte des Augengefässe des Menschen. Anat. Hefte. Bd. XXXVIII, H. 114, S. 1, 1908.

Deyl.-Ueber den Eintritt der Art. cent. Ret. beim Menschen., Anat. Anzeig. Bd. II, S. 687, 1896.

Intern. Congress, Moscow, 1897.

Henkel, Fr. - Beiträge zur Entwickel. des menschlichen Auges. Anat. Hefte, Bd. X H. 33, S. 485, 1898.

Hess.- Arch.f. Ophthal., Bd. XXXVI, H. 1, 1890.

Juler, F.-Trans. Ophthal. Soc. U.K., Vol. XLVI, 1926. 
Naumoff,--Ueber einige path. anat. Veränderungen im Augengrunde bei neugebor. Kindern. Arch.f. Ophthal., Bd. XXXVI.

Parsons.-The pathology of the eye. Vol. III, pt. i, 1906

Schleich. - Mittheilungen aus der ophthal. Klinik in Tübingen. 1884.

Silcock, A. Quarry.-Trans. Ophthal. Soc. U.K., Vol. XX, 1900.

Strahl.-Zur Entwickel. des menschl. Auges. Anat. Anzeig. Bd. XIV, 1898.

Stumpf and Sicherer.-Beiträge zur Geburtshilfe u. Gynaek. Bd. XIII, S. $408,1909$.

Thomson, W. E. and Buchanan, L.-A clinical and pathological account of some of the injuries to the eye of the child during labour. Trans. Ophthal. Soc. U.K., Vol. XXIII, p. 296, 1903.

von Hippel, E.-Pathologico-anatomical changes in the eyes of the new-born. Arch f. Ophthal., Bd XLV.

Vossius.-Beiträge zur Anat. des. Nervus opticus. Arch. f. Ophthal., Bd. XXIX, H. iv, 1883.

Williamson-Noble.-Proc. Ophthal. Sec. Roy. Soc. Med., Vol. XIX, No. 8, p. 14, June, 1926.

Zimmermann.-Klin. Monatsbl.f. Augenheilk., Bd. XXXV, 1897.

\title{
TONOMETRY : A TONOMETER WITH CONVEX PLUNGER
}

BY

\author{
HJ. SCHIÖTZ \\ OSLO
}

IN my article "Tonometry" in the Brit. Jl. of. Ophthal., 1920, were described my attempts to introduce a change in the construction of the tonometer, together with, the significance of the various parts. Under the heading "The Plunger," I recorded certain measurements obtained respectively with plungers having the ordinary concave end-surface, a plane surface, and a convex surface. They showed a surprising difference in the deflections of the pointer, especially as between the concave and the convex surfaces.

As stated in my previous article, my laboratory experiments were made on a small metal drum closed above by a thin rubber membrane as a substitute for the eye, the drum being connected with a water-manometer, and the connection being opened or closed by means of a tap immediately below the drum. The results obtained respectively with the concave and convex plungers, and with open and closed connection, were shown in a table here reproduced (Table I). With a low manometric pressure $(30 \mathrm{~cm}$. $\mathrm{H}_{2} \mathrm{O}$ ) and open connection the deflection differed by about $8 \mathrm{~mm}$. With increasing pressure the difference diminished, but even at $80-90 \mathrm{~cm}$. $\mathrm{H}_{2} \mathrm{O}$, when the concave plunger put the pointer at 0 , the convex put it at $3-4 \mathrm{~mm}$., and even with a pressure of $120 \mathrm{~cm}$. it still gave a deflection of $1.6 \mathrm{~mm}$.

This great difference was surprising but the explanation is very simple: in each case the plunger sinks into the membrane and 